School of Medicine, Winston-Salem, NC showed that both performed equally well in clinical efficacy and bioequivalency. (Oles KS et al. Neurology June 1992; 42:1147-1153.)

\title{
VALPROATE METABOLITES AND HYPERAMMONEMIA
}

The association between valproate metabolism (VPA) and VPA induced hyperammonemia was studied at Hirosaki University Hospital, Japan. In 53 monopharmacy patients, plasma $\mathrm{NH}_{3}$ levels did not depend on age, VPA dosage or serum levels and showed a negative correlation with the 4-en metabolite of VPA. In polypharmacy patients, plasma $\mathrm{NH}_{3}$ levels were significantly higher, while 2-en VPA serum level and bilirubin were lower than in monopharmacy patients. (Kondo $\mathrm{T}$ et al. Is 2-propyl-4-pentonoic acid (4-en), a hepatotoxic metabolite of valproate, responsible for valproateinduced hyperammonemia? Epilepsia May/June 1992; 33:550-554.) (Reprints: Dr. S. Kaneko at Department of Neuropsychiatry, Hirosaki 036, Japan.)

COMMENT. This study indicates that young age and high VPA serum levels are not risk factors for hyperammonemia induced by VPA and 4en metabolite is not causally related to this adverse effect. These authors had previously reported that young age, polypharmacy, and high VPA serum level enhance the susceptibility to VPA hepatotoxicity by altering the metabolism of VPA and by increasing the conversion of VPA to 4-en, the most toxic VPA metabolite (see Ped Neur Briefs March 1992, $\underline{6}: 21)$.

In 43 children with epilepsy who were treated with VPA monotherapy or polytherapy, serum levels of copper were significantly lower than in normal control patients, whereas serum zinc levels were not altered. (Kaji M et al. Epilepsia May/June 1992; $\underline{33: 555-557 .)}$

Valproate and carbamazepine, and in a lesser frequency, phenytoin and phenobarbital, were the most common causes of red blood cell macrocytosis in children in a study from the Children's Medical Center, Dallas, TX (Pappo AS et al. Pediatrics June 1992; 89:1063-1067). Macrocytosis and pancytopenia may be the first manifestation of bone marrow failure and aplastic anemia. An MCV of more than $90 \mathrm{fL}$ in a patient taking antiepileptic medications deserves careful monitoring.

\section{CEREBROVASCULAR DISEASE}

\section{IDIOPATHIC STROKE}

Of 4 children with idiopathic stroke syndrome examined at the Department of Neurosciences and Pediatrics, UMD-New Jersey Medical School and the University of Rochester Medical Center, all 4 were heterozygous for human leukocyte antigen (HLA-B51). Control samples from 3 patients with non-idiopathic stroke syndrome failed to reveal the HAL-B51 marker. (Mintz M, Epstein LG, Koenigsberger MR. Idiopathic childhood 
stroke is associated with human leukocyte antigen (HLA)-B51. Ann Neurol June 1992; 31:675-677.) (Correspondence: Dr. Mintz, Department of Neurosciences, UMD-New Jersey Medical School, MSB-H506, 185 South Orange Avenue, Newark, NJ 07103.)

COMMENT. The finding of a common immunogenetic marker in children with idiopathic stroke syndrome suggests a genetic predisposition and susceptibility. The authors suggest that host factors, possibly triggered by transient viral precipitants, may contribute causally to these vascular occlusions.

Delayed onset hemiparesis and vascular thrombosis may occur approximately 6 weeks after primary varicella zoster virus infection and may explain some cases of misdiagnosed idiopathic stroke in children. (Bodensteiner JB, et al. Clinical features of vascular thrombosis following varicella. AJDC Jan 1992; 146:100-102.) The importance of this clinical entity is emphasized in an editorial (Lancet June 13, $1992 ;$ 339:1449-1450). The prognosis was good regardless of therapy and all patients recovered completely or nearly completely. The MRI was more sensitive than CT or angiography in demonstrating infarction of the basal ganglia and/or internal capsule. The delay in onset of the hemiparesis may result from the time taken for the vascular media to be infected with the virus.

\section{CVA WITH NEUROFIBROMATOSIS TYPE I}

A two year old developmentally delayed girl with neurofibromatosis type I and a sudden onset of left sided hemiparesis is reported from the Children's National Medical Center and George Washington University School of Medicine, Washington, D.C. There was no history of sickle cell disease or hypertension. The hemiparesis gradually improved and the patient received aspirin, $80 \mathrm{mg}$. daily. Four months later there was a left focal seizure and an acute progression of the left hemiparesis. At 5 years of age the patient presented with sudden right-sided weakness and right focal seizure. Cerebral angiography revealed bilateral distal internal carotid arterial occlusion. (Gorelick MH et al. Progressive occlusive cerebrovascular disease in a patient with neurofibromatosis type I. Clin Pediat May 1992; 31:313-315.) (Correspondence: Kenneth N. Rosenbaum, M.D., Department of Medical Genetics, Children's National Medical Center, 111 Michigan Avenue NW, Washington, D.C. 20010.)

COMMENT. Moyamoya may be seen in association with a number of systemic conditions including NF-1 or as a distinct disease entity of unclear etiology. Occlusion of the intracranial arteries is a rare complication of NF-1 and the progressive occlusion noted in this case appears to be unique.

The gene for NF-1 has been mapped to chromosome 17 and closely linked DNA markers have made accurate diagnosis by linkage analysis possible in most cases of familial NF-1. DNA testing by linkage analysis on 24 individuals with a family history of NF-1 and on 9 couples who requested testing for prenatal diagnosis was found useful as an adjunct to the clinical diagnosis 1) in children less than 6 years 